\title{
Electronic Health Records and Ambulatory Quality
}

\author{
Zackary D. Berger, MD, PhD \\ Johns Hopkins General Internal Medicine, Department of Medicine, Baltimore, MD, USA.
}

J Gen Intern Med 28(9):1132

DOI: $10.1007 / \mathrm{s} 11606-013-2474-5$

(c) Society of General Internal Medicine 2013

To the Editor-Kern et al. performed a valuable service in attempting to determine whether adoption of electronic health records (EHRs) is related to quality of care. ${ }^{1}$ Their study is well done and supports the connection between EHRs and success on Healthcare Effectiveness Data and Information Set (HEDIS) measures. It is telling, however, that the authors assume equivalence between quality and such process measures. While some HEDIS measures are indeed associated with improved clinical outcomes - for example, a higher rate of hemoglobin A1C testing is associated with improved glycemic control ${ }^{2}$ - this is not the case with all measures. For example, whether increasing rate of mammography is associated with improved mortality has been shown recently to be something of an open question. ${ }^{3}$

This to take nothing away from the published study, but merely to point out that we should not define quality a priori as "conforming to widely used process measures," without keeping in mind that the connection between such measures and outcomes is not a foregone conclusion. Perhaps we should be saying that this EHR-driven improvement is in "process quality."

Corresponding Author: Zackary D. Berger, $M D$, PhD; Johns Hopkins General Internal Medicine, Department of Medicine, $601 \mathrm{~N}$ Caroline St Suite 7143, Baltimore, MD 2128, USA (e-mail: zberger1@Jhmi.edu).

\section{REFERENCES}

1. Kern LM, Barrón Y, Dhopeshwarkar RV, Edwards A, Kaushal R, HITEC Investigators. Electronic health records and ambulatory quality of care. J Gen Intern Med. 2013;28(4):496-503.

2. Harman JS, Scholle SH, Ng JH, Pawlson LG, Mardon RE, Haffer SC, Shih S, Bierman AS. Association of Health Plans' Healthcare Effectiveness Data and Information Set (HEDIS) performance with outcomes of enrollees with diabetes. Med Care. 2010;48(3):217-23.

3. Bleyer A, Welch HG. Effects of three decades of screening mammography on breast-cancer incidence. N Engl J Med. 2012;367:1998-2005. 